\title{
APPLICABILITY OF THE OBLA METHOD FOR DETERMINATION OF TRAINING WORKLOADS IN FEMALE SOCER PLAYERS
}

\author{
Stanislav Tzvetkov \\ National Sports Academy "Vassil Levski", Sofia, Bulgaria
}

\begin{abstract}
The concept of onset of blood lactate accumulation (OBLA) has been widely used for training workload control through analysis of blood lactate (BL) concentration. However, according to modern specialists setting exercise intensity on the basis of this method entails a risk of prescribing insufficient training workload, which would not cause adequate increase of an athlete's functional capacity. In this research we have examined the effect of applying the OBLA method when setting the training workload of qualified female soccer players. The subjects of the research were Bulgarian national team female soccer players. They carried out a maximum exercise treadmill test using an incremental protocol with rest periods between steps. BL samples were taken during the rest periods. The lactate anaerobic threshold (LT) was determined using the lactate dynamics breakpoint method. OBLA (defined as the intensity of exercise at which BL concentration reached $4.0 \mathrm{mmol} / \mathrm{l}$ ) was also identified. We analysed the values of workload and heart rate corresponding to the individual $L T\left(S_{L T}, H R_{L T}\right)$ and to OBLA $\left(S_{O B L A}, H R_{O B L A}\right)$. It was established that in six $(60 \%)$ of the athletes the $H R_{O B L A}$ values were significantly lower compared to $H R_{L T}\left(H R_{O B L A}=70 \div 74 \%\right.$ of $H R_{\max } ; H R_{L T}=79 \div 84 \%$ of $H R_{\max }$ ). $B L$ concentrations of $4.0 \mathrm{mmol} / \mathrm{l}$ were registered at significantly lower work intensity compared to the individual LT. The obtained results show that planning training load intensity using OBLA method would most likely fail to induce considerable improvement in the functional capabilities of the examined female soccer players.
\end{abstract}

Keywords: onset of blood lactate accumulation, training workload, female soccer

\section{INTRODUCTION}

The need for a comprehensive analysis of workloads with limitating impact on the sports performance determines the conduct of numerous studies on the relation between the dynamics of the blood lactate concentration and the performed motor activity. The concept of lactate anaerobic threshold has been introduced as a result of the conducted researches. Despite the fact that this concept is commonly applied in the modern sports and training practice, there is an active discussion within the scientific community about its particular interpretation. A convincing confirmation of this view is Grancharov's publication (1997) that is popular in Bulgaria, wherein a multitude of methods for analysing the dynamics of the blood lactate concentration during intensive physical workload have been discussed. The publication of Bosquet et al. (2002) confirms the lack of a uniform opinion. A number of various methodological approaches for determination of the lactate anaerobic threshold have been reviewed in this comprehensive scientific research. In accordance with the recognised scientific guides
(Kenney et al., 2011; McArdle et al., 2009; Thompson et al., 2009), the classic methodology for calculation of the lactate anaerobic threshold is based on defining the beginning of a considerable increase in the blood lactate concentration ("lactate dynamics breakpoint”) during incremental exercise tests.

A widely used practical approach for setting the training load intensity via an analysis of the blood lactate concentration is the so-called "OBLA method" that specifies the onset of blood lactate accumulation (OBLA) (Hech et al., 1985; Kindermann et al., 1979; Sjodin, Jacobs, 1981). The authors of this method stipulate that the running speed at which blood lactate concentration reaches value of $4.0 \mathrm{mmol} / \mathrm{l}$ corresponds to a very high degree $(87 \div 92 \%)$ with the attained average speed during competition (Sjodin, Jacobs, 1981). They summarise that inclusion of exercise bouts at blood lactate concentration of $4.0 \mathrm{mmol} / \mathrm{l}$ during training considerably enhances the athletes' functional characteristics and could successfully be used for prediction of race results. From a practical point of 
view the OBLA method has a significant advantage because it is more easily applied and lessens the possibility of a subjective error (Hech et al., 1985). This advantage determines the widespread application of this methodological approach for setting training exercise intensity in various sports disciplines.

Conversely, nowadays other specialists consider that the use of the OBLA method in the training process poses the risk of insufficiently effective training workload that would not considerably increase their functional working capacity (Kenney et al., 2011; McArdle et al., 2009).

The purpose of this study is to analyse the applied value of the OBLA method when prescribing the intensity of the training exercises in qualified female soccer players.

\section{METHODS}

The subjects of the study were 10 female soccer players (average age of $21.7 \pm 2.8$ years) from the representative team of the National Sports Academy (Sofia) and the national women's soccer team of Bulgaria. All of the subjects were clinically healthy and injury-free. Before participating in the study, each subject was familiarized with the experimental procedure and informed of the risks associated with the experimental protocol.

The examined athletes conducted an intermittent maximal exercise test on a treadmill using an incremental stepwise model with initial speed of 6.0 $\mathrm{km} / \mathrm{h}$ and speed increase at each step by $1.2 \mathrm{~km} / \mathrm{h}$. The duration of each step was two minutes with 40 seconds breaks between steps. The respiratory indices and the electrocardiographic characteristics of the athletes were registered using Oxycon Pro cardio-pulmonary testing device (Erich Jaeger, $\mathrm{GmBH}$ \& Co Wuerzburg, Germany). During the functional test blood lactate concentration was analysed and capillary blood was taken during the pauses after the third (speed of $8.4 \mathrm{~km} / \mathrm{h}$ ), the fourth (speed of $9.6 \mathrm{~km} / \mathrm{h}$ ), the fifth (speed of $10.8 \mathrm{~km} / \mathrm{h}$ ), the sixth (speed of $12.0 \mathrm{~km} / \mathrm{h}$ ), the seventh (speed of 13.2 $\mathrm{km} / \mathrm{h}$ ), and the eighth (speed of $14.4 \mathrm{~km} / \mathrm{h}$ ) step; capillary blood was tested using a calibrated lactate analyser (Accutrend Lactate, Roche). In addition, the heart rate of the examined persons was also registered at the end of each specified step.

We analysed the following functional parameters: blood lactate concentration dynamics in the course of the exercise test; work capacity (treadmill speed) and heart rate corresponding to the individual lactate anaerobic threshold $\left(\mathrm{S}_{\mathrm{LT}}, \mathrm{HR}_{\mathrm{LT}}\right)$ and onset of blood lactate accumulation $\left(\mathrm{S}_{\mathrm{OBLA}}, \mathrm{HR}_{\mathrm{OB} \text { - }}\right.$ $\left.{ }_{\mathrm{LA}}\right)$. The individual lactate anaerobic threshold was determined using the lactate dynamics breakpoint method where the start of a significant increase in lactate concentration was specified. Onset of blood lactate accumulation (OBLA) was specified on the basis of the concept that during an incremental exercise test OBLA corresponds to the exercise intensity corresponding to blood lactate concentration of $4.0 \mathrm{mmol} / \mathrm{l}$. The obtained values for $\mathrm{S}_{\mathrm{OBLA}}, \mathrm{S}_{\text {LT' }}$ $\mathrm{HR}_{\mathrm{OBLA}}$ and $\mathrm{HR}_{\mathrm{LT}}$ were statistically processed with a Student's $t$ test, preceded by a distribution normality check of the respective samples with the Kolmogorov-Smirnov and Shapiro-Wilk tests (Stuart et al., 1999). The $t$ criterion was used for evaluation of the statistical results with a standard level of significance $\left(\mathrm{p}^{*}<0.05\right)$ (SPSS 17).

\section{RESULTS}

The registered high maximum values of lactate $\left(\mathrm{La}_{\max }>9.5 \mathrm{mmol} / \mathrm{l}\right)$ confirm that all examined individuals have conducted an objectively verified maximum exercise. During the statistical processing of the obtained data a statistically significant difference $\left(\mathrm{p}^{*}<0.05\right)$ was ascertained both between the values of $S_{\text {OBLA }}$ and $S_{\mathrm{LT}}$ and between the values of the $\mathrm{HR}_{\mathrm{OBLA}}-\mathrm{HR}_{\mathrm{LT}}$ pair. Compared the values of the $\mathrm{S}_{\mathrm{OBLA}}-\mathrm{S}_{\mathrm{LT}}$ pair, the analysed values of the $\mathrm{HR}_{\mathrm{OBLA}}{ }^{-}$ $\mathrm{HR}_{\mathrm{LT}}$ pair feature a considerably lower correlation coefficient $\left(\mathrm{r}_{\mathrm{S}(\mathrm{OBLA})-\mathrm{S}(\mathrm{LT})}=0.61 ; \mathrm{r}_{\mathrm{HR}(\mathrm{OBLA}) \text {-HR(LT) }}=0.29\right)$. This result corresponds to the accepted view that heart rate has high interindividual variability that the results presented in Table 1 show. 
Table 1. Values of the registered heart rate and treadmill speed corresponding to the onset of blood lactate accumulation (HROBLA, SOBLA) and lactate anaerobic threshold (HRLT, SLT).

\begin{tabular}{|c|c|c|c|c|}
\hline & $\mathrm{HR}_{\mathrm{OBLA}}($ beats/min $)$ & $\mathrm{S}_{\mathrm{OBLA}}(\mathbf{k m} / \mathbf{h})$ & $\mathrm{HR}_{\mathrm{LT}}($ beats/min $)$ & $\mathrm{S}_{\mathrm{LT}}(\mathbf{k m} / \mathbf{h})$ \\
\hline Subject 1 & 137 & 9.6 & 146 & 10.8 \\
\hline Subject 2 & 136 & 9.6 & 150 & 10.8 \\
\hline Subject 3 & 143 & 10.8 & 154 & 12.0 \\
\hline Subject 4 & 149 & 10.8 & 149 & 10.8 \\
\hline Subject 5 & 152 & 10.8 & 152 & 10.8 \\
\hline Subject 6 & 141 & 9.6 & 153 & 12.0 \\
\hline Subject 7 & 145 & 10.8 & 158 & 9.6 \\
\hline Subject 8 & 146 & 9.6 & 146 & 10.8 \\
\hline Subject 9 & 157 & 10.8 & 157 & 12.0 \\
\hline Subject 10 & 139 & 10.8 & 160 & \\
\hline
\end{tabular}

The detailed analysis of the results found that the lower than the $\mathrm{HR}_{\mathrm{LT}}$ values $\left(\mathrm{HR}_{\mathrm{LT}}=79 \div 84 \%\right.$ of $\mathrm{HR}$ registered $\mathrm{HR}_{\mathrm{OBLA}}$ values $\left(\mathrm{HR}_{\mathrm{OBLA}}=70 \div 74 \%\right.$ of $\left.\mathrm{HR}-{ }_{\max }\right)$ (Table 2$)$. Respectively, lower $\mathrm{S}_{\mathrm{OBLA}}$ values $\left(\mathrm{S}_{\mathrm{OB}-}\right.$ ${ }_{\max }$ ) of six $(60 \%)$ of the examined female soccer ${ }_{\mathrm{LA}}=69 \div 75 \%$ of $\mathrm{S}_{\max }, \mathrm{S}_{\mathrm{LT}}=80 \div 86 \%$ of $\mathrm{S}_{\max }$ ) were also players from the national team were considerably registered in these soccer players.

Table 2. A comparison of heart rate and treadmill speed at OBLA and lactate anaerobic threshold (lactate dynamics breakpoint method) expressed as a percentage of the maximum registered values in six of the examined female soccer players.

\begin{tabular}{|l|l|l|}
\hline & Corresponding heart rate & Corresponding treadmill speed \\
\hline OBLA method & $70 \div 74 \%$ of $\mathrm{HR}_{\max }$ & $69 \div 75 \%$ of $\mathrm{S}_{\max }$ \\
\hline Lactate dynamics breakpoint method & $79 \div 84 \%$ of $\mathrm{HR}_{\max }$ & $80 \div 86 \%$ of $\mathrm{S}_{\max }$ \\
\hline
\end{tabular}

The graphical presentation of lactate dynamics $\mathrm{km} / \mathrm{h}$ ). Furthermore, it is evident that lactate con(Figure 1) confirms the shown results. In agree- centration of $4.0 \mathrm{mmol} / \mathrm{l}$ is achieved at relatively ment with the data in Table 1 it is shown that in low exrcise intensity compared to the registered regard to all examined female players the onset of maximum ergometric capacity ( $\operatorname{Smax}=13.83 \pm 0.33$ blood lactate accumulation (OBLA) corresponds $\mathrm{km} / \mathrm{h}$ ).

to workloads of low or medium intensity $(9.6 \div 10.8$

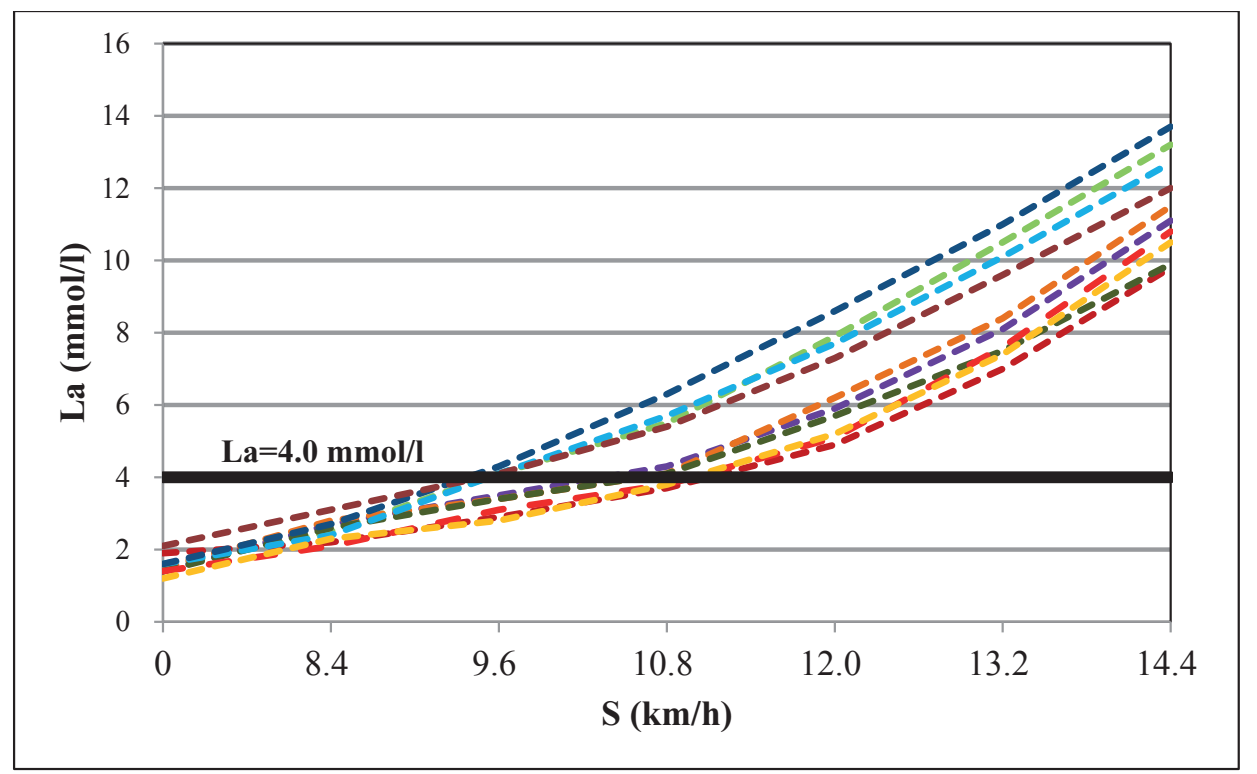

Figure 1. Dynamics of the registered lactate values. 


\section{DISCUSSION}

Specialists consider that to comprehensively analyse the dynamics of the blood lactate concentration during a maximal exercise test, the test has to be performed until exhaustion (Iliev et al., 1982). McArdle et al. (2009) point out that objective maximum wokload is verified by maximum blood lactate concentration registered in the end of a functional test above $9.0 \mathrm{mmol} / \mathrm{l}$. The analysis of the obtained data found that all of the tested soccer players have achieved maximum lactate values higher than 9.5 $\mathrm{mmol} / \mathrm{l}$. This result confirms that the examined female soccer players have completely revealed their overall maximal capabilities and have carried out the functional test to exhaustion.

In addition, it could be emphasized that in view of the characteristics of the soccer game, the athletes participating in the research have shown good maximum work capacity. This is confirmed by both the results achieved in this research $\left(\mathrm{S}_{\max }=13.83\right.$ $\pm 0.33 \mathrm{~km} / \mathrm{h}$ ) and the published results from other researches (Tsekova, 2014; Tsekova, 2015) in which the examined individuals have participated. In this context, it would not be correct to assume that the lower values of $\mathrm{HR}_{\mathrm{OBLA}}$ and $\mathrm{S}_{\mathrm{OBLA}}$ are registered due to low functional capabilities of the examined players as a result of which they have prematurely terminated the maximal exercise test. Moreover, based on the registered high maximum values of lactate $\left(\mathrm{La}_{\max }>9.5 \mathrm{mmol} / \mathrm{l}\right)$ it could reasonably be assumed that the examined female soccer players have achieved an objectively verified maximum physical workload. Based on these circumstances we assumed that the registered low values of $\mathrm{HR}_{\mathrm{OB}}$ ${ }_{\mathrm{LA}}$ and $\mathrm{S}_{\mathrm{OBLA}}$ have been due to the specific methodological aspects that characterise the applied OBLA method.

Since the onset of blood lactate accumulation and lactate anaerobic threshold are considered two different methodological approaches, it is logical that both functional parameters correspond to different intensity of exercise workload (Bosquet et al., 2002). In agreement with this, the results of this research (Figure 1) show that in most of the examined female soccer players these functional characteristics were registered at different exercise intensity. It should be pointed out that most of the examined individuals showed lactate concentration of $4.0 \mathrm{mmol} / \mathrm{l}$ at lower speed compared to the lactate dynamics breakpoint. Seiler, Tennessen (2009) assume that the most optimal improvement of the functional aerobic capabilities of qualified athletes is observed when their training is conducted at $75 \%$ to $85 \%$ of their maximum heart rate. The presented results show that six of the examined players have registered $\mathrm{HR}_{\mathrm{OBLA}}$ values $\left(\mathrm{HR}_{\mathrm{OBLA}}=70 \div 74 \%\right.$ of $H R_{\max }$ ) below this range. In this context, it could reasonably be assumed that setting the training intensity of these athletes on the basis of the OBLA method would entail the use of inadequate training programmes (in terms of intensity). It is also obvious that applying the $\mathrm{HR}_{\mathrm{LT}}$ values $\left(\mathrm{HR}_{\mathrm{LT}}=79 \div 84 \%\right.$ of $\mathrm{HR}_{\max }$ ) for setting the training intensity would considerably enhance the aerobic capacity of these six soccer players.

On the basis of the above it could be expected that using the OBLA method for setting the training load intensity would most likely fail to induce considerable improvement in the functional capabilities of the examined female soccer players. This is in full agreement with the opinion of Santos-Concejero et al. (2013) who emphasize that applying the OBLA method for setting the exercise intensity in the training process poses significant constraints.

According to them, due to this circumstance the OBLA method is not recommended to be used as a main methodological approach when setting the training workload of athletes. This scientific view is also supported by Baptista et al. (2005) who comment that the OBLA method is insufficiently precise and point out that its use entails a risk of undervaluing the physiological individual characteristics in the dynamics of blood lactate concentration. In this respect, they recommend to use the so-called " $D_{\max }$ method" for analysing blood lactate concentration during functional testing of athletes.

In conclusion it could be summarised that the use of the OBLA method for setting the training workload of the examined female soccer players creates prerequisites for using training workload of inadequately low intensity which could limit the effect of the performed training process. With regard to qualified athletes, it is recommended that the OBLA method should be applied in combination with an additional corrective analysis of the dynamics of the blood lactate concentration by specifying the lactate dynamics breakpoint and by applying the $\mathrm{D}_{\max }$ method. 


\section{REFERENCES}

Baptista, R., Gandolfi de Oliveira, L., Bosak de Figueiro, G. et al. (2005). Lactate threshold in rowers: comparison between two methods of determination. Revista Brasileira de Medicina do Esporte, Vol. 11(4), pp. 233236e.

Bosquet, L., Leger, L., Legros, P. (2002). Methods to determine aerobic endurance. Sports Medicine, Vol. 32(11), pp. 675-700.

Grancharov, N. (1997). Anaerobniyat prag-sashtnost $i$ prilozhna stoynost $v$ sporta. Natsionalna Sportna Akademiya, Sofiya.// Грънчаров, H. (1997). Анаеробният праг-същност и приложна стойност в спорта. Национална Спортна Академия, София.

Hech, H., Mader, A., Hess, G. et al. (1985). Justification of the $4 \mathrm{mmol} / \mathrm{l}$ lactate threshold. International Journal of Sports Medicine, Vol. 6, pp. 117-130.

Iliev, I., Kosev, R., Grancharov, N. (1982). Prilozhna fiziologiya $v$ sporta. Meditsina i fizkultura, Sofiya.// Илиев, И., Косев, Р., Грънчаров, Н. (1982). Приложна физиология в спорта. Медицина и физкултура, София.

Kenney, L., Wilmore, J., Costill, D. (2011). Physiology of sport and exercise. $5^{\text {th }}$ ed., Human Kinetics Press, Champaign.

Kindermann, W., Simon, G., Kuel, J. (1979). The significance of the aerobic-anaerobic transition for the determination of workload intensities during endurance training. European Journal of Applied Physiology, Vol. 42, pp. 25-34.

McArdle, W., Katch, F., Katch, V. (2009). Exercise Physiology: Energy, Nutrition and Human Performance. $7^{\text {th }}$ ed., Williams \& Wilkins, Philadelphia.

Santos-Concejero, J., Granados, C., Irazusta, J. et al. (2013). Time to exhaustion at the onset of blood lactate accumulation in runners of different athletic ability.
Revista Brasileira de Medicina do Esporte, Vol. 19(4), pp. 297-302.

Seiler, S., Tennessen, E. (2009). Intervals, thresholds, and long slow distance: the role of intensity and duration in endurance training. Sportscience, Vol. 13, pp. 32-53. Available at: http://www.sportsci.org/

Sjodin, B., Jacobs, I. (1981). Onset of blood accumulation and marathon running performance. International Journal of Sports Medicine, Vol. 2, pp. 23-26.

Stuart, A., Ord, K., Arnold S. (1999). Kendall's Advanced Theory of Statistics. $6^{\text {th }}$ ed., Arnold, London.

Thompson, W., Gorden, N., Pescatello, L. et al. (2009). ACSM's Guidelines for Exercise Testing and Prescription. $8^{\text {th }}$ ed., Williams \& Wilkins, Philadelphia.

Tsekova, S. (2014). Vazmozhnosti za usavarshenstvane sportnata podgotovka na futbolistkite. Sport i nauka, №2, рр. 3-9.// Цекова, С. (2014). Възможности за усъвършенстване спортната подготовка на футболистките. Спорт и наука, 6р. 2, с. 3-9.

Tsekova, S. (2015). Rolya na mediko-biologicheskite testiraniya pri etapniya kontrol i otsenka $\mathrm{v}$ sportnata podgotovka na zheni futbolistki. Sport i nauka, №2, pp. 93-101.// Цекова, С. (2015). Роля на медико-биологическите тестирания при етапния контрол и оценка в спортната подготовка на жени футболистки. Спорт и наука, бр. 2, с. 93-101.

\section{Corresponding autor: Tzvetkov Stanislav}

$\mathrm{MD}, \mathrm{PhD}$, Associate Professor, Department of "Sports medicine" National Sports Academy "Vassil Levski", Studentski grad, 21, Acad. Stefan Mladenov Str. Sofia 1700, Bulgaria Email: st.tzvetkov@gmail.com 